\title{
MENGASAH KEMAMPUAN MENGAJAR MELALUI LITERASI
}

\author{
Saverinus Gordisona' Achmad Supriyanto² Agus Timan ${ }^{3}$ \\ Email: sonysaveriand@gmail.com \\ Universitas Negeri Malang, Pascasarjana, Program Studi Manajemen Pendidikan \\ Jl. Semarang No. 5, Kota Malang
}

\begin{abstract}
Like a professional in his field, the teacher is expected to have good competence as a person who teaches and educates. Literacy programs are one way to hone skills in conducting learning with the support of the knowledge they have. This paper aims to learn the professionalism of teachers at the Kalam Kudus Malang Middle School in carrying out daily learning. The method used is through interviews. One of the problems found below is that teaching ability is quite low. This is the result of an increase in literacy skills in the teacher class. This problem can be solved by creating a special literacy program by synergizing the role of universities and schools.
\end{abstract}

Keywords: Literacy, Learning

\begin{abstract}
Abstrak: Layaknya seorang yang profesional dalam bidangnya, guru diharapkan memiliki kompetensi yang baik sebagai seorang yang mengajar dan mendidik. Program literasi merupakan salah satu cara untuk mengasah kemampuan dalam melaksanakan pembelajaran dengan memperluas pengetahuan yang dimiliki. Tulisan ini bertujuan untuk mengetahui profesionalitas guru di SMP Kalam Kudus Malang dalam melaksanakan pembelajaran seharihari. Metode yang yang digunakan adalah melalui analisis fish bone dan wawancara. Diperoleh salah satu permasalahan yang diemukan adalah kemampuan mengajar yang cukup rendah. Ini sebagai akibat dari kurangnya keterampilan berliterasi di kalangan guru. Permasalahan ini dapat dipecahkan dengan membuat program khusus literasi dengan mensinergikan peran perguruan tinggi dengan sekolah.
\end{abstract}

Kata Kunci: Literasi, Pembelajaran

\section{PENDAHULUAN}

Pesatnya perkembangan yang terjadi saat ini memberikan dampak berbeda-beda bagi setiap orang. Tidak terkecuali dengan dunia pendidikan, era modern telah memberikan pengaruh terhadap sistem serta proses pendidikan yang berlangsung. Hangat dibicarakan bahwa dunia saat ini dihadapkan pada era revolusi indutri 4.0. perubuhan pola kehidupan pada masyarakat akan terjadi seiring konsep serupa merambah pola perilaku dan kebutuhan. Pendidikan melalui pembelajaran yang baik diharapkan mampu menangkal tantangan yang terjadi akibat perubahan ini. Heckeu dkk seperti yang dikutip oleh Yahya (20I8) menyebutkan beberapa tantangan revolusi industri 4.0 bagi perkembangan masyarakt, diantaranya tantangan ekonomi, tantangan sosial, tantangan teknis, tantangan lingkungan, tantangan politik dan aturan.

Guru sebagai pengajar dan pendidik memiliki tanggung jawab khusus dalam penanaman nilai dan norma, pengetahuan, dan keterampilan bagi peserta didiknya. Hal ini telah diperjelas sebagai tujuan utama pendidikan nasional yang tertuang dalam UU no 20 tahun 2003 tentang Sistem Pendidikan Nasional. Guru merupakan aktor yang memiliki kedudukan yang strategis dalam upaya memanusiakan manusia (Saondi dan Suherman, 2009). Dalam rangka menghasilkan individu yang berakhlak serta memiliki pengetahuan luas maka diperlukan kualitas tenaga pendidik serta budaya dan iklim pembelajaran yang baik pula (Rasyid dan Mansur, 20I2). $\mathrm{Hal}$ ini mengikhtiarkan bahwa proses pemblajaran cukup berhubungan dekat dengan kompetensi seorang tenaga pendidik dalam mengelolah kelas, menyajikan materi pembelajaran yang baik, serta keterampilannya dalam merencanakan pembelajaran serta perangkat dan 
media lain yang menarik bagi siswa. Hal ini tentu guru perlu mendapatkan dukungan yang penuh oleh lingkungan sekolah yang mampu menyediakan tempat, waktu, dan sarana untuk mendapatkan informasi yang terus berkembang.

Tingginya permintaan terhadap kualitas diri saat ini menggiring setiap orang untuk mampu mengolah kemampuannya secara mandiri. Program literasi gepar dikampanyekan oleh banyak pihak sebagai langkah mencerdaskan diri diera modern ini. Akan tetapi yang perlu digarisbawahi apakah semua orang di negeri ini memiliki kesadaran untuk berliterasi?. Berdasarka hasil survei yang dilakukan Most Littered Nation In the World pada tahun 2016 menunjukan bahwa Indonesia berada pada urutan 60 dari 61 negara dalam hal minat membaca. Rangking ini berada dibawah negara berkembang lainnya yang berada dikawasan ASIA seperti Thailand peringkat ke 59, Malaysia peringkat 53, dan China peringkat ke 19. Selanjutnya Survei dilakasanakan oleh Programme for International Student Assesment (PISA) tahun 2015 menunjukan posisi negara Indonesia menempati peringkat 62 dari 72 negara yang disurvei. Hal ini menunjukan bahwa masih rendahnya tingkat literasi masyarakat.

Penguasaan literasi berupa keterbukaan dan kemudahan informasi yang diperoleh sangat penting dalam implementasi pembelajaran saat ini. Atas dasar ini program literasi dapat dijadikan progam utama sekolah dalam mendongkrak pengetahuan dan keterampilan semua warga sekolah terutama para guru (Hasugian, 2008). Menurut Kemendikbud (2017) gerakan literasi dalam pembelajaran bertujuan untuk meningkatkan kualitas hidup. Lanjutnya program literasi disekolah dapat diimplementasikan dalam kegiatan kurikuler, kokurikuler, dan ekstrakurikuler. Hal ini mengikhtiarkan bahwa literasi memiliki kedudukan yang strategis dalam perkembangan tenaga pendidik dan siswa disekolah. Tenaga pendidik menjadi unsur utama implementasi pendidikan perlu untuk membenahi kualitas diri melalui pembiasaan berliterasi.

Akbar (2017) mengemukakan setidaknya ada tiga hambatan utama dalam penerapan literasi disekolah, diantaranya, (I) program literasi merupakan hal yang masih jarang ditemukan dalam perumusan program peningkatan kualitas SDM diberbagai lembaga pendidikan; (2) keterbatasan ruang/sumber untuk memperoleh informasi yang terus berkembang; (3) lingkungan sekolah yang kurang mendukung budaya literasi. Untuk memudahkan para pendidik memperoleh informasi terhadap perkembangan yang terus menerus terjadi, maka tulisan ini mencoba menggali peran perguruan tinggi dalam dalam mendukung program literasi.

Negara Indonesia hingga saat ini tumbuh sebagai satu negara yang besar dan memiliki sistem pendidikan yang baik. Menengok kembali hakekat pendidikan nasional yang tertuang dalam UU RI No 20 tahun 2003 tentang Sistem Pendidikan Nasional bahwa "pendidikan nasional berfungsi mengembangkan kemampuan dan membentuk watak serta peradaban bangsa yang bermartabat dalam rangka mencerdaskan kehidupan bangsa...". Hal ini mengikhtiarkan bahwa perumusan sistem pendidikan di Indonesia telah mempertimbangkan SDM sebagai aset utama peradaban suatu bangsa. SDM menjadi salah satu sektor strategis yang perlu terus dikembangkan. SDM yang baik dapat memberikan dampak baik pula pada perkembangan dan peradaban bangsa.

Terkait dengan TQM, Goetsch dan Davis sebagaimana dikutip Nasution, (2005) dan Tjiptono \& Diana (200I) menyebutkan beberapa unsur TQM diantaranya adalah berfokus pada kepuasan pelanggan, fokus terhadap kualitas, menggunakan metode ilmiah, orintasi pada tujuan jangka panjang, mengedepankan upaya teamwork, memiliki siklus evaluasi, pendidikan dan pelatihan, memiliki tujuan terencana, terkendali, dan pelibatan. Perguruan tinggi dapat memainkan banyak aktor dalam penerapan TQM disekolah sebagai upaya peningkatan kualitas SDM dengan berlandas unsur pelibatan. Itika (2019) memberikan gambaran tentang bagaimana seharusnya maemanajemen sumber daya manusia berdasarkan teori Role Behaviour Theory. Menurutnya membangun sumber daya manusia selayaknya berfokus pada peningkatan peran informasi bagi setiap orang yang diberdayakan. Rianti (20II) menjelaskan bahwa perguruan 
tinggi memiliki kewajiban untuk membentuk masyarakat madanai. Perguruan tinggi menawarkan berbagai peluang untuk mengembangakan sumber daya manusia, serta mempelajari tentang cara membangun sumber daya manusia bagi sesamanya.

Mengingat kembali Tri Dharma perguruan tinggi yaitu, Dharma Pendidikan, Dharma Penelitian, dan Dharma Pengabdian Masyarakat mengingakan kembali akan tanggung jawab yang besar perguruan tinggi dalam membentuk manusia yang bermanfaat bagi manusia lain. Barnet (dalam Sonhadji, 20/8) menyatakan bahwa "perguruan tinggi dewasa ini sudah merupakan superkompleksitas". Perguruan tinggi mencakup tiga peranan besar diantaranya adalah kepemimpinan, penelitian dan pengajaran. Perguruan tinggi merupakan lembaga yang paling aktif melaksanakan aktivitas riset and development bagi masyarakat yang melibatkan tenaga dosen sendiri ataupun oleh mahasiswanya. Aktivitas seperti inilah yang mengikhtiarkan bahwa perguruan tinggi memiliki misi yang besar dalam pembangunan SDM. Hasil-hasil riset dan informasi terbaru dapat memberikan manfaat besar bagi proses pembelajaran disekolah sebagai aset berharga yang terus dibuthkan oleh para pendidik.

Sonhadji dan Huda (2015) mengungkapkan bahwa kebutuhan menyangkut apa yang dibutuhkan. Perguruan tinggi menyediakan akses yang baik terhadap kebutuhan akan SDM setiap orang termasuk para pendidik disekolah. Hal yang sering dijumpai di era modern ini adalah keterbatasan informasi yang diperoleh para pendidik. Kebutuhan akan adanya informasi seperti ini cukup banyak diabaikan oleh mereka yang seharusnya berkapasitas besar untuk mengarahkan tujuan pedidikan. Sebagai suatu langkah revitalisasi program literasi, perguruan tinggi dapat dijadikan basis penyedia informasi, pengelolah informasi, serta pemberi informasi bagi para pendidik disekolah. Selain itu, perguruan tinggi sebagai lembaga pendidikan tertinggi dapat memberikan pelatihan terhadap keterampilan khusus bagi para pendidik dalam merancang pembelajaran yang ada disekolah. Berikut merupakan konsepsi interaksi perguruan tinggi dengan lingkungan eksternal menurut Sonhadji.

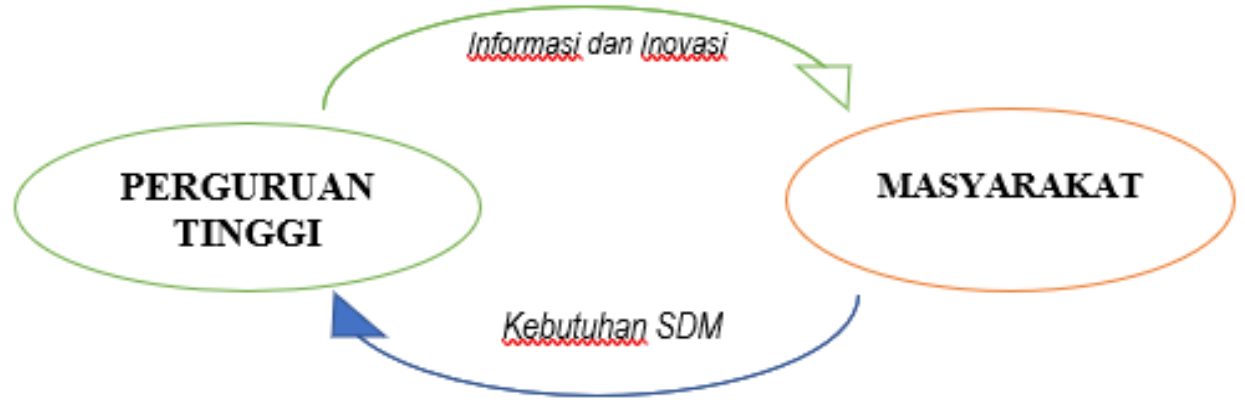

Gambar I. Interaksi Perguruan Tinggi dengan Lingkungan Eksternal

Sonhadji menunjukan bahwa adanya hubungan simbiotik antara perguruan tinggi dengan lingkungan eksternal menyangkut peningkatan SDM, hasil-hasil penelitian, inovasi, serta struktur baru dalam organisasi. Untuk itu perguruan tinggi diharapkan selalu peka terhadap berbagai perubahan lingkungan dan kebutuhan masyarakat dan industri agar outcomes dan impact yang dihasilkan dapat memberikan perubahan bagi tatanan kehidupan masyarakat. Sekolah menjadi salah satu sektor yang dinilai perlu mendapatkan perlakuan yang lebih. Peran serta perguruan tinggi dalam memberikan informasi, inovasi, serta keterampilan yang dibutuhkan oleh para pendidik menjadi salah satu upaya untuk membangun kemampuan mengajar para guru di sekolah.

\section{METODE}

Artikel ini menggunakan pendekatan kualitatif. Pengumpulan data melalui dua teknik yaitu menggunakan analisis fish bone untuk menggali penyebab utama terjadinya masalah 
rendahnya kecakapan guru dalam mengajar dan teknik wawancara dengan pihak SMP Kalam Kudus Malang untuk menggali informasi tentang keterlibatan perguruan tinggi dalam pembangunan sumberdaya manusia melalui literasi. Analisis data yang digunakan adalah teknik analisis deskriptif.

\section{HASIL DAN PEMBAHASAN}

Data hasil wawancara menunjukan bahwa SMP Kalam Kudus malang memiliki kendala dalam proses pembelajaran yang diterapkannya sehari-hari. Permasalahan ini berkaitan erat dengan kecakapan para guru dalam pembelajaran. Guru SMP Kalam Kudus Malang menjelaskan beberapa faktor yang mempengaruhi permasalahan tersebut diantaranya adalah masih ditemukannya tenaga pendidik yang melaksanakan pembelajaran dikelas bertentangan dengan bidang yang menjadi kompetensinya, rendahnya motivasi guru dalam mengajar, serta yang paling utama adalah adanya ketidakpedulian terhadap pengembangan kualitas diri sebagai pendidik dan pengajar melalui kegiatan berliterasi. Keterampilan menulis literasi dalam pendidikan yang paling mendasar menurutnya adalah kemampuan untuk membuat silabus, merancang dan memodifikasi RPP, serta menambah wawasan sesuai dengan perkembangan ilmu pengetahuan saat ini. "informasi mengenai ilmu pengetahuan saat inikan berkembang sangat cepat, oleh karena itu guru-guru kita sebisanya mengetahui itu dan siap memberikan pemahaman terhadap anak muridnya" berikut kutipan wawancara dengan seorang guru SMP Kalam Kudus Malang. Berikut merupakan hasil analisis fish bone di SMP Kalam Kudus Malang.

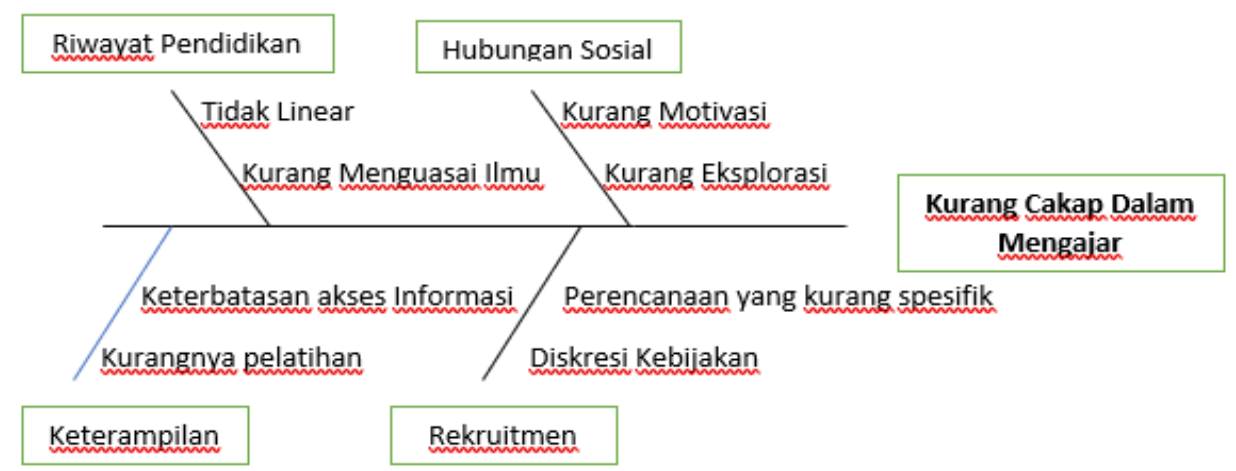

Gambar 2. Hasil Analisis Fish Bone

Berdasarkan data, SMP Kalam Kudus Malang memiliki guru berjumlah 25 orang. Terdapat sembilan orang tenaga pendidik mengampuh mata pelajaran tidak selaras dengan bidang kompetensinya. sebagai contoh mata pelajaran fisika diampuh oleh guru yang bukan memiliki latar pendidikan fisika melainkan ilmu fisika murni. Kondisi seperti ini memberikan celah adanya pembelajaran yang hanya mengoptimalkan ranah kognitif tapi lemah dalam mendidik karena tanpa didadasari oleh pemahaman pedagogis.

Untuk mengatasi permasalahan ini, SMP Kalam Kudus Malang membuka diri terhadap pelibatan pihak eksternal dalam memberikan solusi yang terbaik. Selain dari Kementrian Pendidikan dan Kebudayaan, SMP Kalam Kudus juga mendatangkan praktisi dan pakar pendidikan dari universitas yang berada di jawa timur untuk memberikan pembekalan tambahan yang berkaitan dengan pengetahuan dan teknis pembelajaran yang baik dikelas. Para guru juga aktif mengikuti berbagai pelatihan, workshop dan seminar yang diselenggarakan oleh universitas disekitarnya.

\section{Pembahasan}

Pelaksanaan pembelajaran dengan mengasah kemampuan mengajar oleh para guru di SMP Kalam Kudus Malang melalui literasi masih rendah. Beberapa penyebab yang diungkapkan oleh pihak SMP Kalam Kudus adalah (I) guru-guru kurang memiliki motivasi untuk berliterasi; (2) guru-guru cenderung pasif dalam mengatasi banyaknyapermasalahan dalam pembelajaran; 
(3) masih kurang adanya komitmen yang kuat dari pihak sekolah untuk menyusun bentuk program khusus yang mengarah pada pembiasaan literasi; (4) keterbatasan akses dalam memperoleh informasi yang cepat, tepat, dan sesui dengan tuntutan pebelajaran saat ini. Permasalahan seperti ini dinilai perlu menemukan solusi yang baik dengan harapan adanya perubahan pada kulitas pelayanan pembelajaran yang disekolah.

Manajemen sumber daya manusia di SMP Kalam Kudus Malang yang menempatkan beberapa guru pada bidang yang kurang relevan dengan latar pendidikannya memberikan dampak terhadap kemampuan berliterasi dalam pembelajaran. Program pelatihan dan pengenalan ranah pedagogis menjadi fokus utama penyelesaian masalah yang selama ini dilakukan. Hal ini sangat bermanfaat karena para guru yang tidak memiliki latar belakang sebagai calon pengajar dan pendidik mendapatkan pengetahuan sebagai bekal melaksanakan pembelajaran dikelas. Joseph M. Juran (dalam Nasution, 20I5) mengemukakan bahwa salah satu langkah untuk memperbaiki kualitas adalah melalui tindakan pelatihan dan melaksanakan proyek-proyek yang mengasah keterampilan. Langkah SMP Kalam Kudus Malang melaksanakan pelatihan, mengikuti workshop dan seminar dengan pihak universitas meruapakan salah satu wujud penerapan TQM yang pernah dilaksanakan.

\section{KESIMPULAN}

Program literasi bertujuan untuk memperbaiki kualitas diri setiap orang melalui ilmu pengetahuan yang diterimanya. Guru sebagai ujung tombak pendidikan perlu untuk membenahi kualitas diri melalui program literasi agar dapat melaksanakan pembelajaran yang baik disekolah. Keterbatasan akses informasi yang sering dialami para guru disekolah dapat diselesaikan melalui salah satu caranya yaitu mensinergikan peran perguruan tinggi dengan sekolah dalam bentuk pelatihan, seminar dan shared innovation and development. Penerapan TQM di SMP Kalam Kudus Malang tampak dalam beberapa kegiatan yang melibatkan perguruan tinggi sesuai dengan unsur pelibatan yang dikemukan oleh Goetsch dan Davis. Hal ini dapat diimplikasikan melalui keterlibatan perguruan tinggi dalam memberikan pelaihan dan worksop serta keikutsertaan para guru dalam acara seminar dan pelatihan pembelajaran yang diselenggarakan oleh perguruan tinggi.

\section{DAFTAR RUJUKAN}

Akbar, Aulia. 2017. Membudayakan Literasi Dengan Program 6M Di Sekolah Dasar. Jurnal $\begin{array}{llll}\text { Pendidikan Sekolah Dasar (JPSD), } & \text { 3(I). Dari }\end{array}$ Http://Jurnal.Untirta.Ac.Id/Index.Php/Jpsd/Article/View/I093/2690

Hasugian, Jonner. 2008. Urgensi Literasi Informasi dalam Kurikulum Berbasis Kompetensi di Perguruan Tinggi. Jurnal Studi Perpustakaan dan Informasi, 4(2). Dari https://www.google.com/search?q=Urgensi+Literasi+Informasi+dalam+Kurikulum+B erbasis+Kompetensi+di+Perguruan+Tinggi\&rlz=ICICHWL_enID8I6ID8 I 6\&oq=U rgensi+Literasi+Informasi+dalam+Kurikulum+Berbasis+Kompetensi+di+Perguruan+ Tinggi\&aqs=chrome..69i57.2304j0j7\&sourceid=chrome\&ie=UTF-8\#

Itika, Josephat Stephen. 20II. Fundamentals Of Human Resaurce Management. Afrika: African Studies Centre

Nasution, M. Nur. 2005. Total Quality Management. Jakarta: PT Gramedia Pustaka Utama

Nasution, M. Nur. 20I5. Manajemen Mutu Terpadu. Jakarta: Ghalia Indonesia

Panduan Gerakan Literasi Nasional. 2017. Jakarta: Kementrian Pendidikan dan Kebudayaan Programme for International Student Assesment (PISA). 20I5. OECD

Rasyid, Harun., Mansur. 2012. Penilaian Hasil Belajar. Bandung: CV. Wacana Prima

Rianti. 20I I. Kajian Yuridis Tentang Keberadaan Perguruan Tinggi Negeri Badan Hukum Milik

Negara Dalam Undang-Undang Sistem Pendidikan Nasional. Jurnal Ilmu Hukum, 7 (I 3). 
Dari https://media.neliti.com/media/publications/240035-kajian-yuridis-tentangkeberadaan-pergur-268I6el4.pdf

Saondi, Ondi., Suherman, Aris. 2010. Etika Profesi Keguruan. Bandung: PT. Refika Aditama

Sonhadji, Ahmad. 2018. Manusia Teknologi dan Pendidikan: Menuju Peradaban Baru. Malang: Universitas Negeri Malang

Sonhadji, Ahmad., Huda, Muhammad. 2015. Asesemen Kebutuhan, Pengambilan Keputusan, dan Perencanaan: Merantai dalam Manajemen Pendidikan. Malang: Universitas Negeri Malang

Tjiptono, Fandy dan Diana, Anastasia. 200I. Total Quality Management. Yogyakarta: CV. Andi Offset

UU RI No 20 tahun 2003 tentang Sistem Pendidikan Nasional.

World's Most Literate Nations Ranked. 2016. Dari http://webcapp.ccsu.edu/?news=1767\&data

Yahya, Muhammad. 2018. Era Industri 4.0: Tantangan Dan Peluang Perkembangan Pendidikan Kejuruan Indonesia. Makalah Disampaikan pada Sidang Terbuka Luar Biasa Senat Universitas Negeri Makassar, Makasar, 14 Maret. 